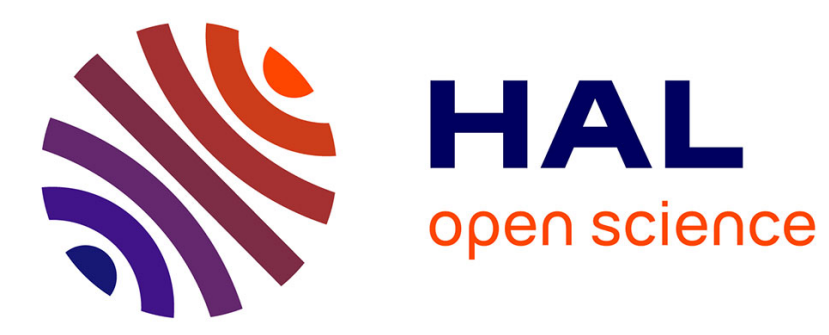

\title{
Solubility and emulsifying properties of kappa casein and its caseinomacropeptide
}

J.M. Chobert, A. Touati, C. Bertrand-Harb, Michèle Dalgalarrondo, M.G. Nicolas

\section{> To cite this version:}

J.M. Chobert, A. Touati, C. Bertrand-Harb, Michèle Dalgalarrondo, M.G. Nicolas. Solubility and emulsifying properties of kappa casein and its caseinomacropeptide. Journal of Food Biochemistry, 1989, 13 (6), pp.457-473. hal-02722039

\section{HAL Id: hal-02722039 \\ https://hal.inrae.fr/hal-02722039}

Submitted on 1 Jun 2020

HAL is a multi-disciplinary open access archive for the deposit and dissemination of scientific research documents, whether they are published or not. The documents may come from teaching and research institutions in France or abroad, or from public or private research centers.
L'archive ouverte pluridisciplinaire HAL, est destinée au dépôt et à la diffusion de documents scientifiques de niveau recherche, publiés ou non, émanant des établissements d'enseignement et de recherche français ou étrangers, des laboratoires publics ou privés. 
ith little loss. Such patatin is without fear of possible

pharose so that sequential ability was not established lor patatin isolation could

Can. J. Bot. 62, 1640 le glycoprotein of potato Hydrophobic Interaction 'entennial Ave., Piscata-

\section{SOLUBILITY AND EMULSIFYING PROPERTIES OF KAPPA CASEIN AND ITS CASEINOMACROPEPTIDE}

\author{
JEAN-MARC CHOBERT', ABDELMADJID TOUATI, CATHERINE BERTRAND- \\ HARB, MICHÈLE DALGALARRONDO and MARIE-GEORGETTE NICOLAS
}

Institut National de la Recherche Agronomique

Laboratoire d'Etude des Interactions des Molécules Alimentaires

B.P. 527

44026 Nantes Cedex03, France

Receired for Publication April 25, 1989

Accepted for Publication July 25, 1989

\begin{abstract}
Kappa-casein A was treated with chymosin in order to isolate the caseinomacropeptide corresponding to the C-terminal 106-169 residues of $\kappa$-casein. Whole casein, $k$-casein and the caseinomacropeptide (CMP) were studied for their water solubility and emulsifying activity. The CMP was soluble over the range of $\mathrm{pH}$ from 1 to 10 , with a "minimum" solubility (88\%) in the range of pH I-5 and a "maximum" solubility (98\%) in the range of pH 5-10. For whole casein and $\mathrm{k}$-casein, at pH values above 5.5, the emulsifying activity increased when $p H$ increased and the maximum value was obtained for very alkaline solutions; for $p H$ values below 4.5 , the increase in emulsifying activity was much more pronounced at $\mathrm{pH}$ 2.5; below pH 2.5, emulsifying activity decreased. For $C M P$, the increase in emulsifying activity was much more pronounced in the acidic range than in the alkaline range. After $24 h$ storage and heating of the emulsion, a large $\mathrm{pH}$-dependant decrease of emulsifying activity (22-60\%) was observed for CMP for pH values below 4.0; under the same conditions, the emulsifying activity of whole casein and $\mathrm{k}$-casein showed a 5-19\% and a 1$21 \%$ decrease, respectively. For $\mathrm{pH}$ values above 6.0, a 22-59\% decrease was observed for CMP as compared to a $1-12 \%$ and a 4-17\% decrease with whole casein and $\mathrm{\kappa}$-casein, respectively.
\end{abstract}

'To whom reprint requests should be addressed.

Journal of Food Biochemistry 13 (1989) 457-473. All Rights Reserved.

(c) Copyright 1989 by Food \& Nutrition Press, Inc., Trumbull, Connecticut. 


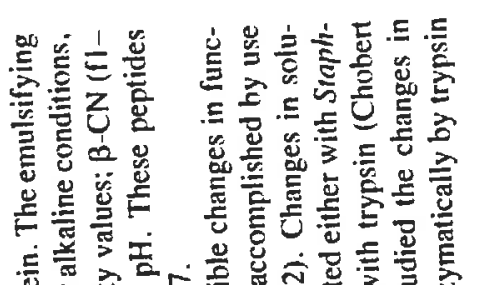

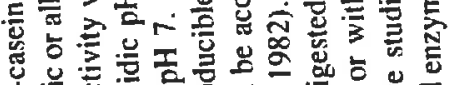

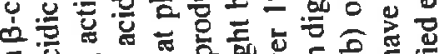

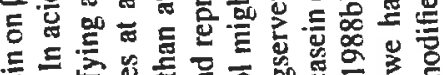

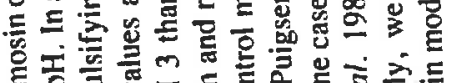

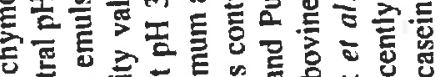

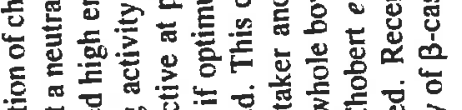

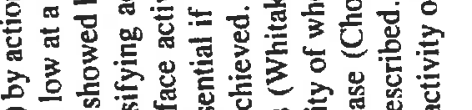
क人

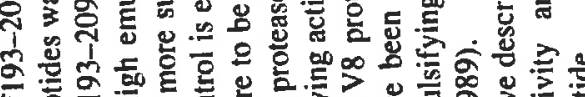

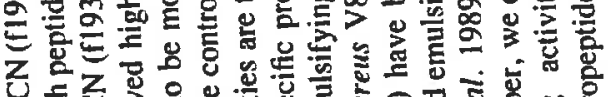

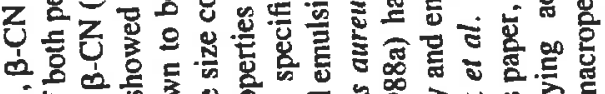

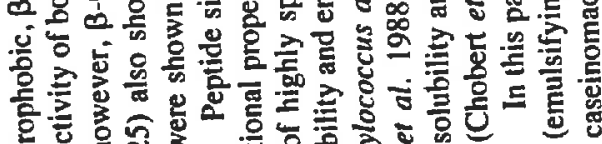

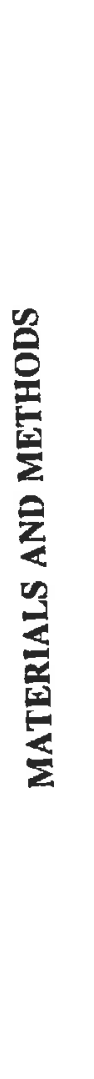

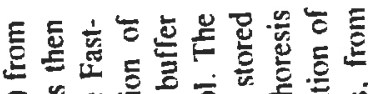

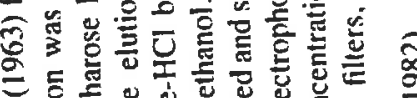

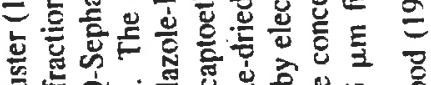

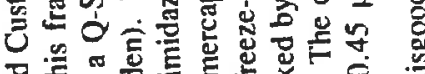

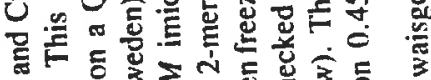

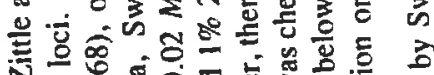

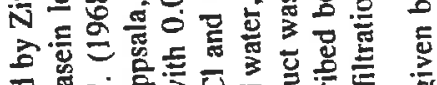

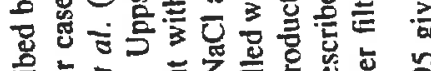

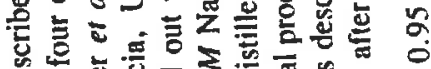

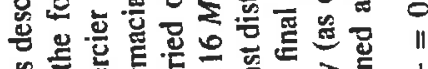

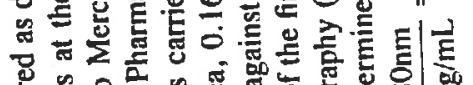

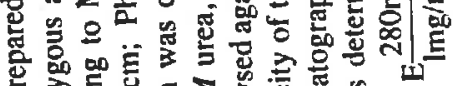

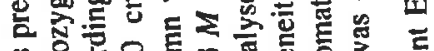

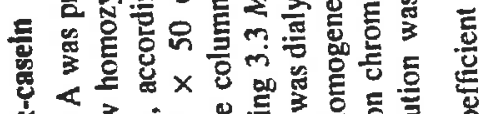

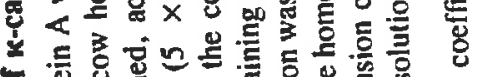

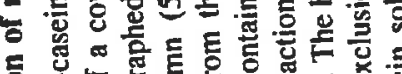

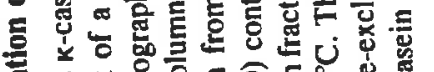

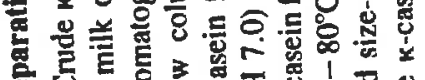

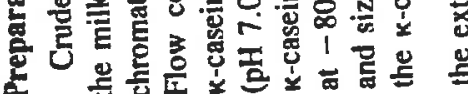

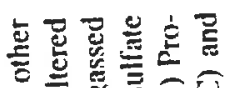

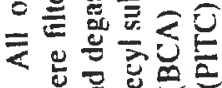

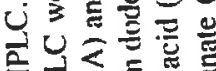

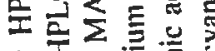

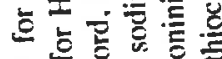

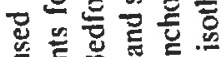

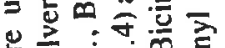

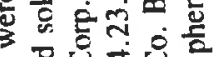
즐

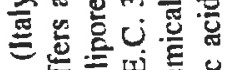

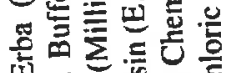
舟 응

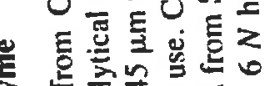

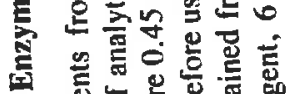

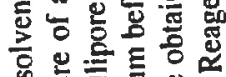

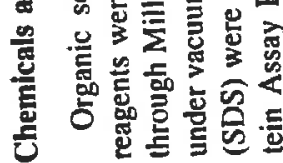

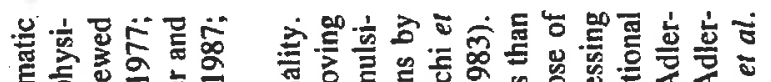

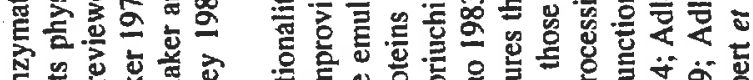

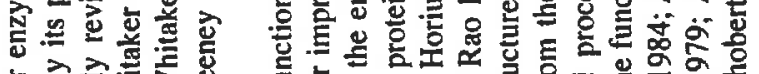

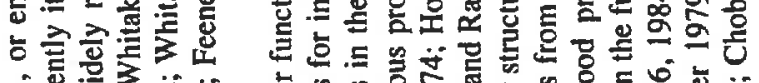

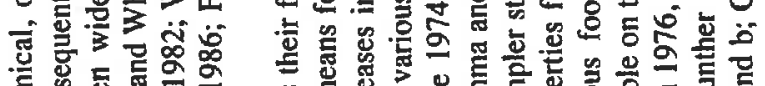

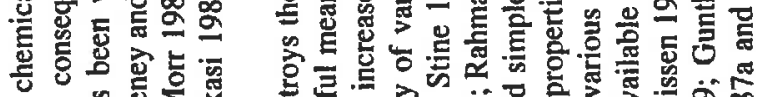

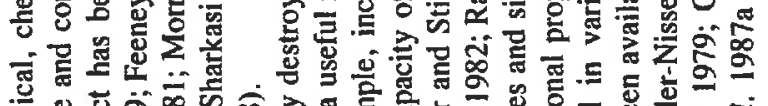

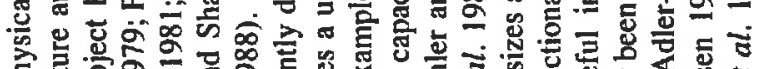

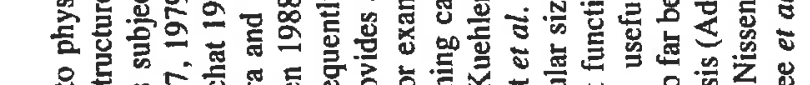

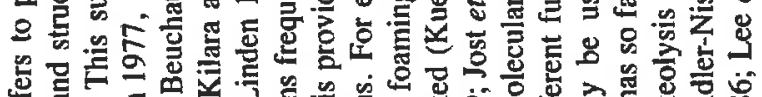

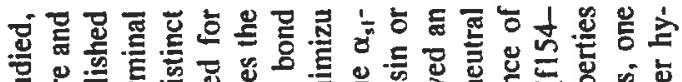

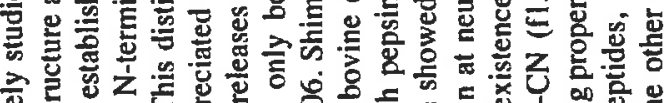

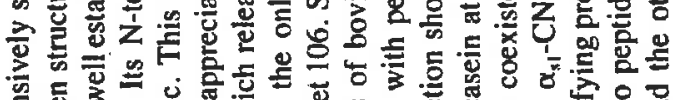

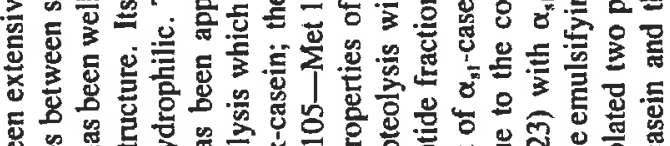

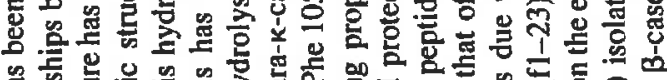

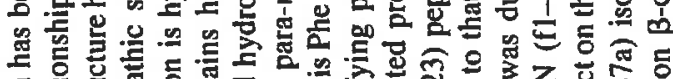

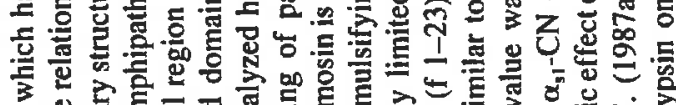
3

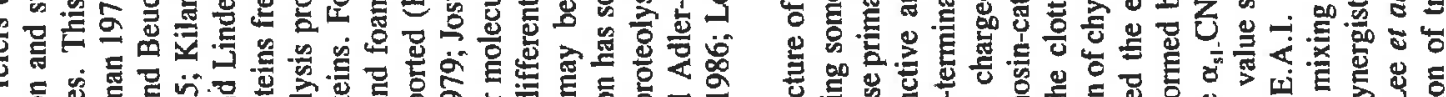

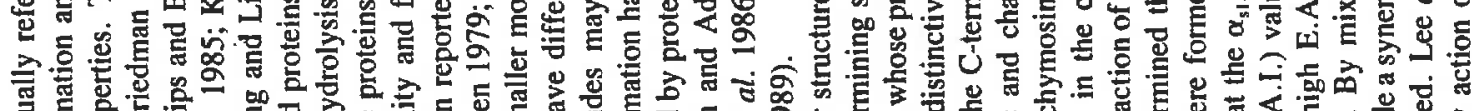

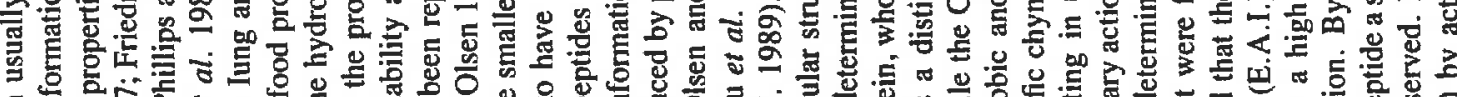

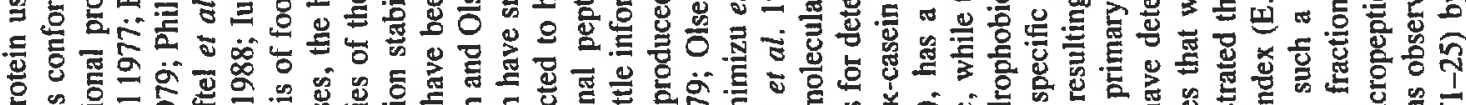

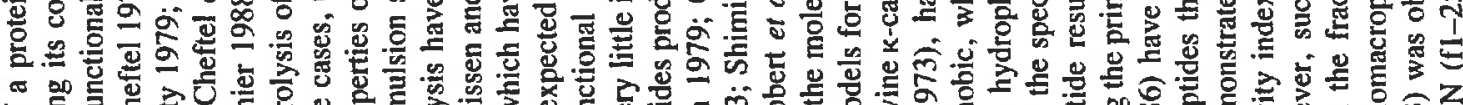

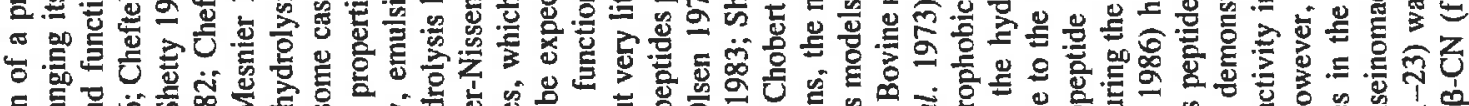

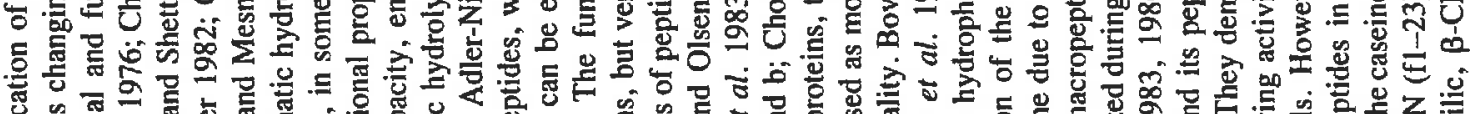

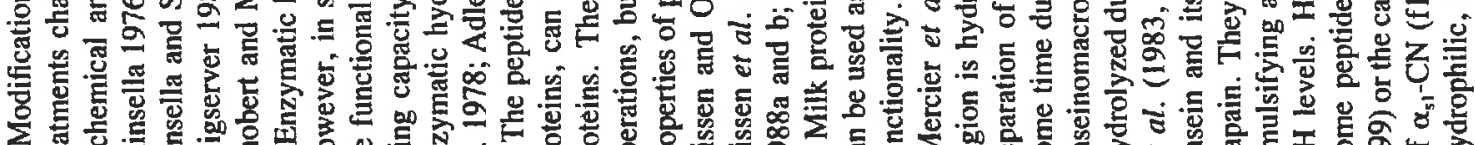

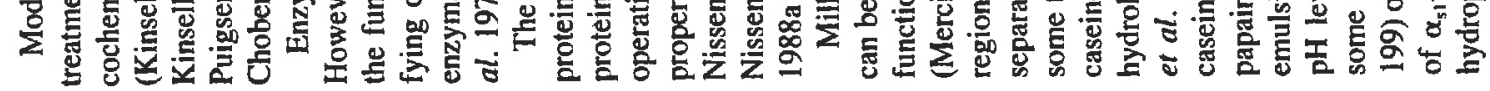




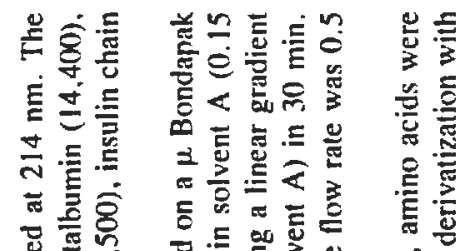

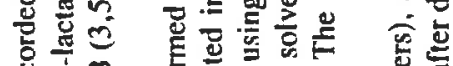

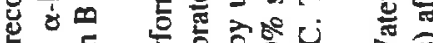

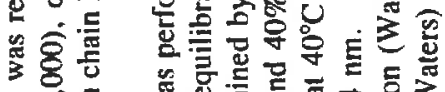

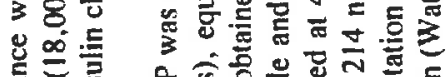

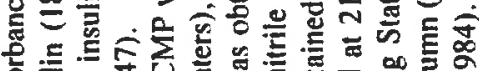

兽言审等

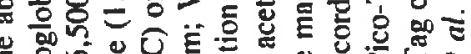
要 通

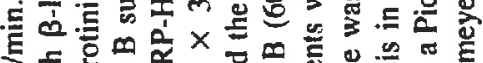

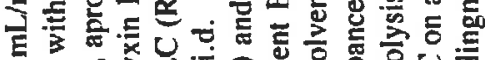
的安有

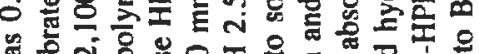

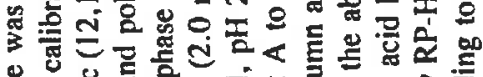

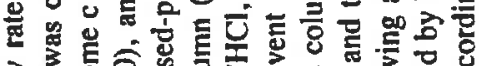

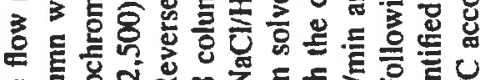

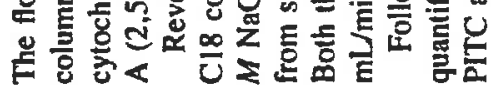

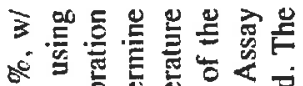

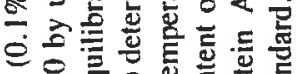

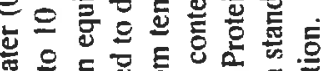

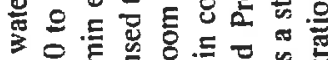

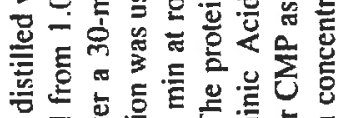

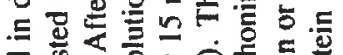

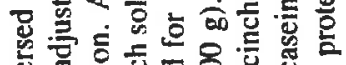

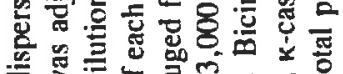

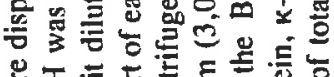

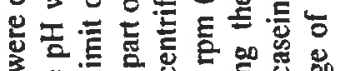
a

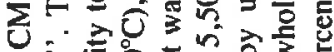

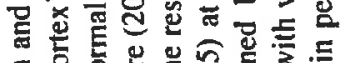

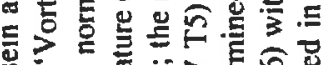

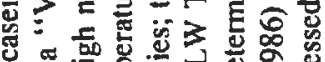

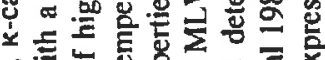

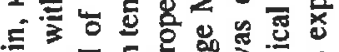
을 列 言 능

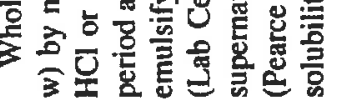

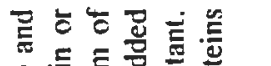

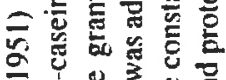

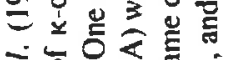

s

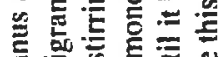

政

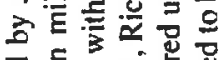

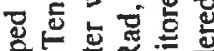

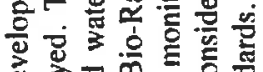

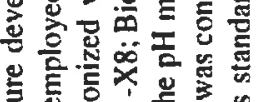

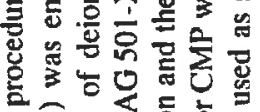

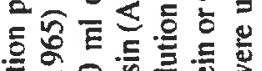

产

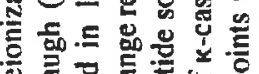

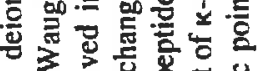

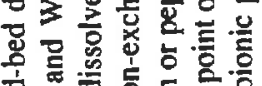

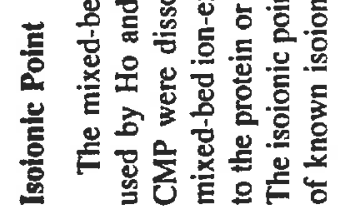

可

宸

政

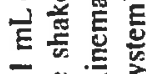

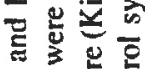

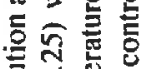

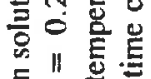

은

so

要

送这

E.

$5 \div$

赔

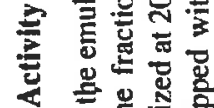

要

密

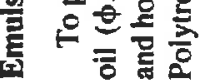

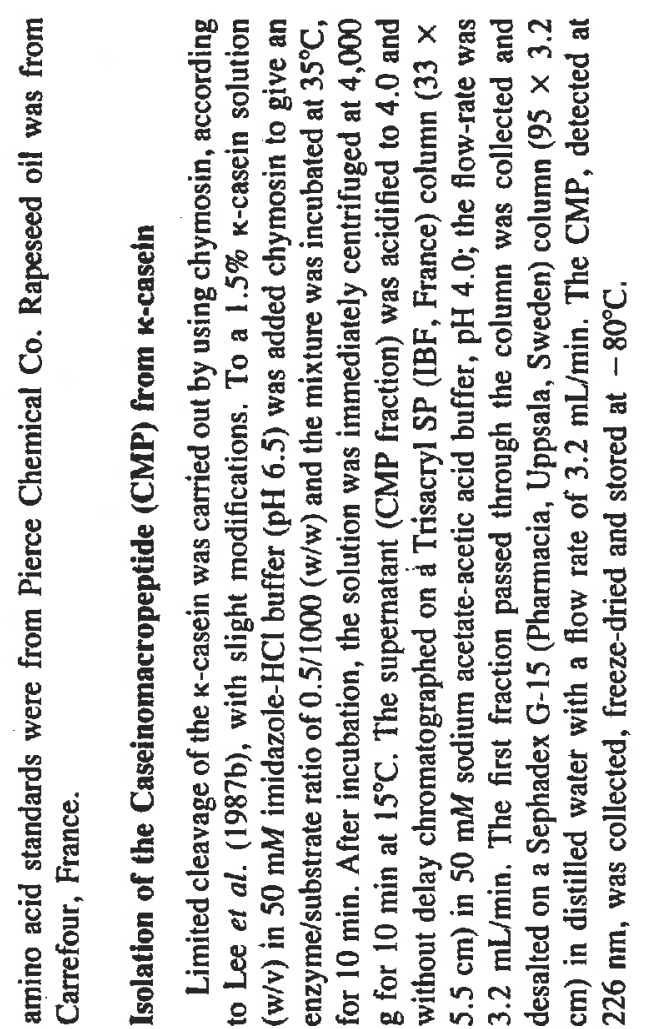

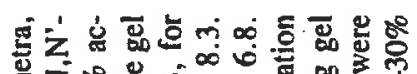

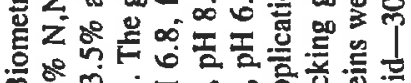

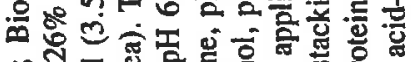

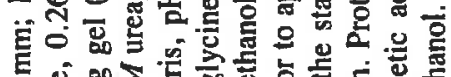
E

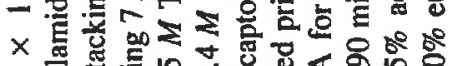

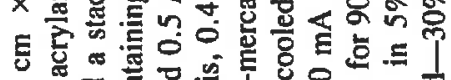

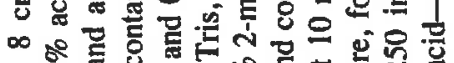
$\times$ 을

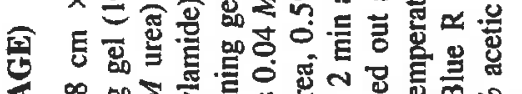

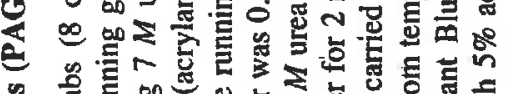

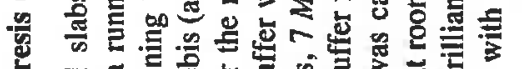

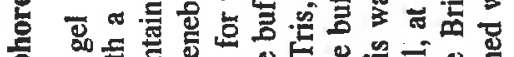

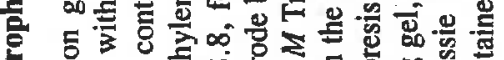

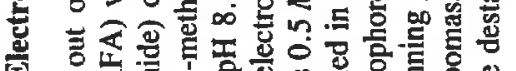

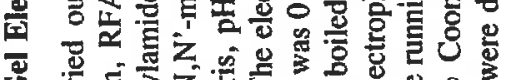

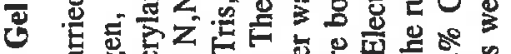

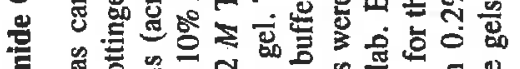
E⿱

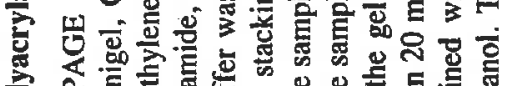

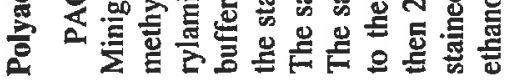

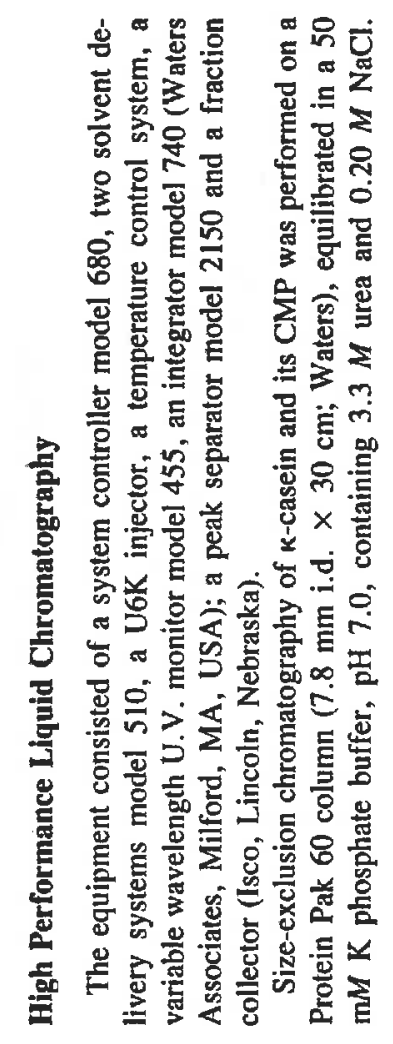




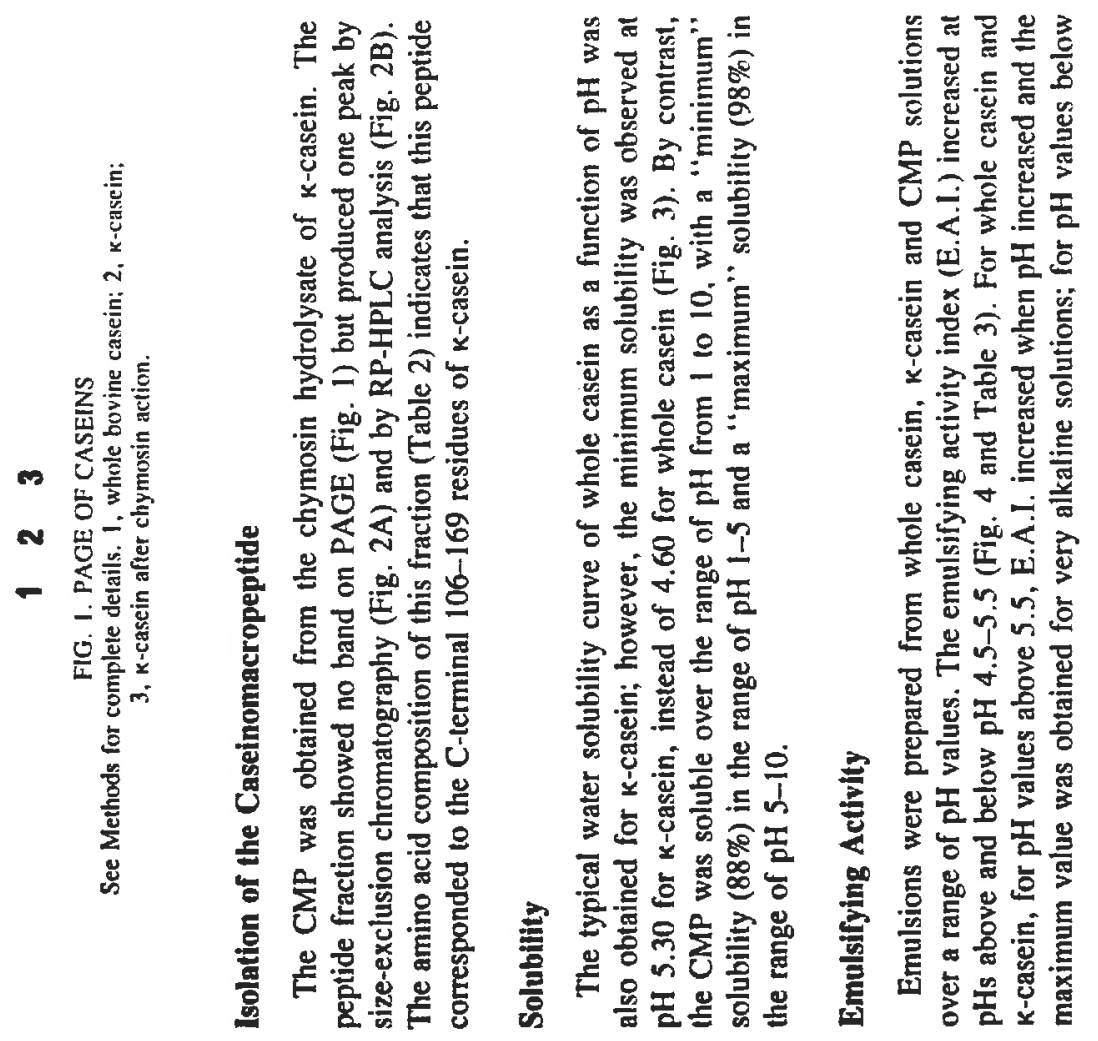

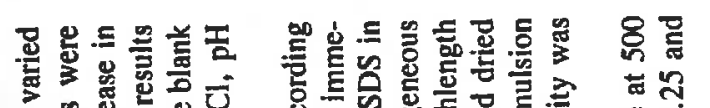

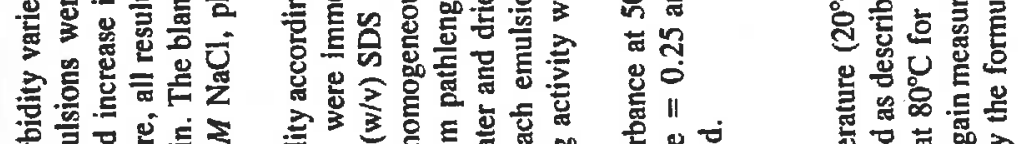
क्ष

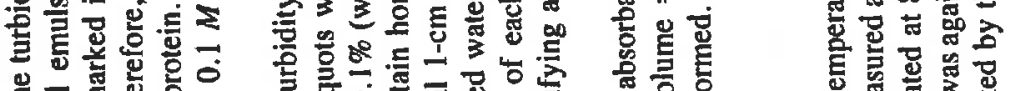

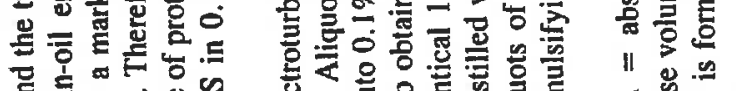

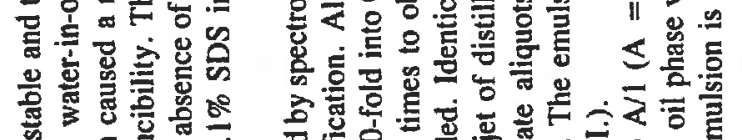

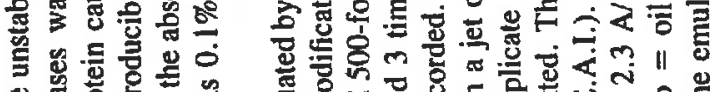

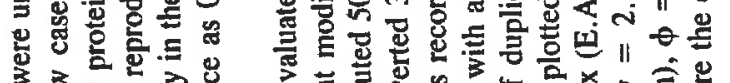

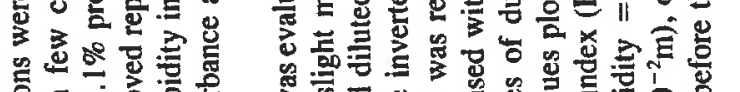

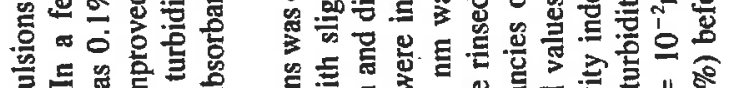

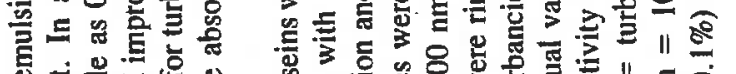

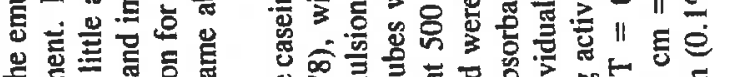

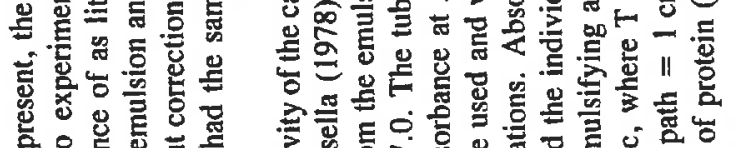

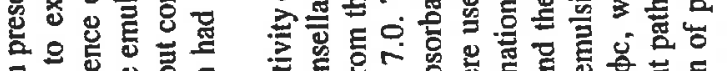

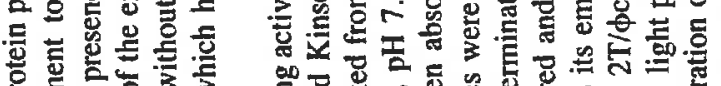

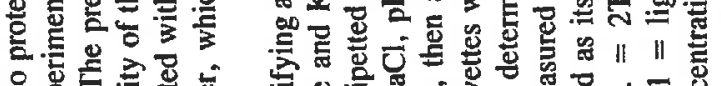

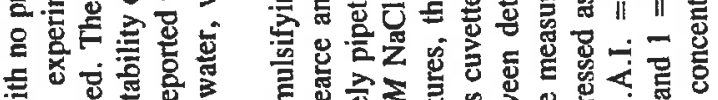

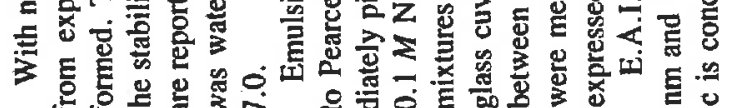

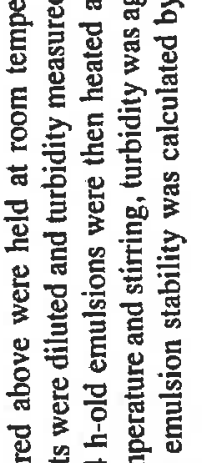

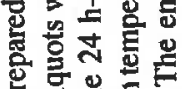

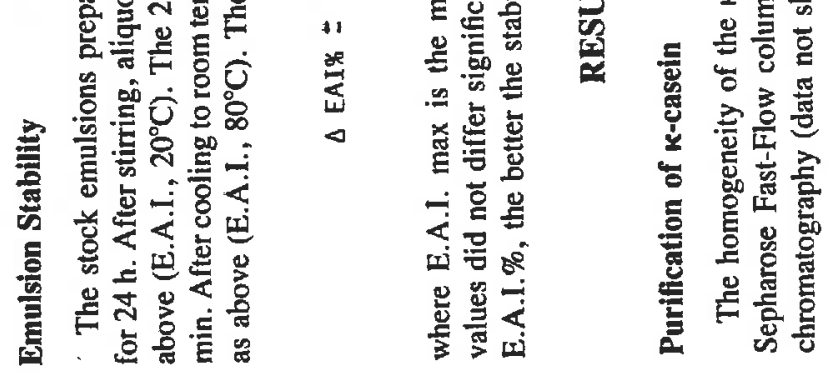




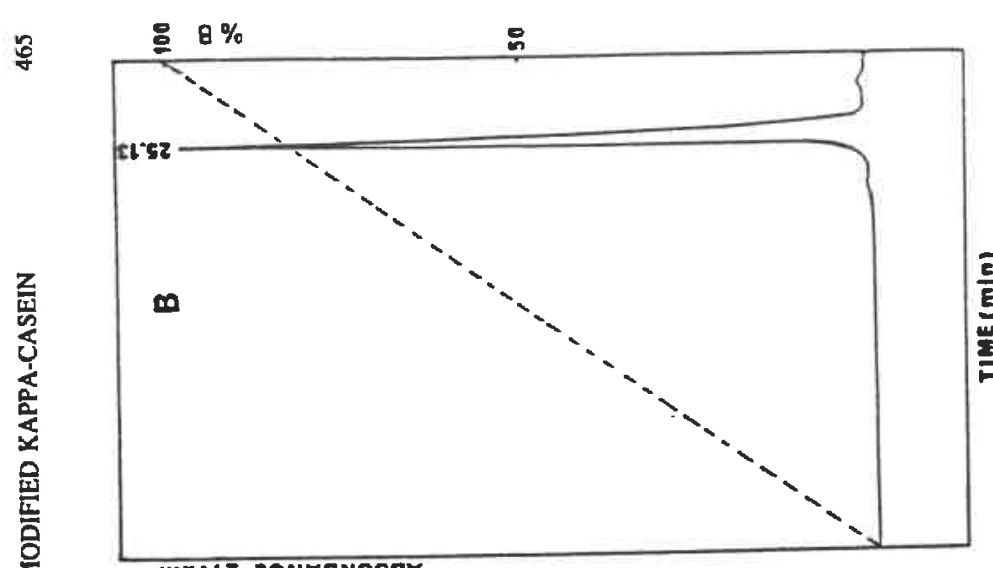

Wutz 35N70yosat

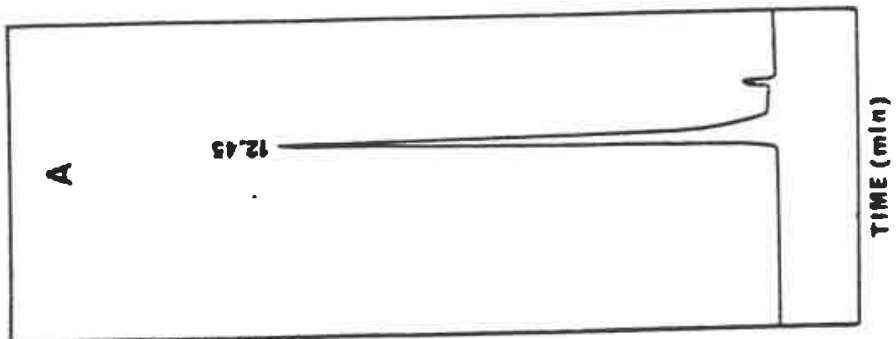

mu

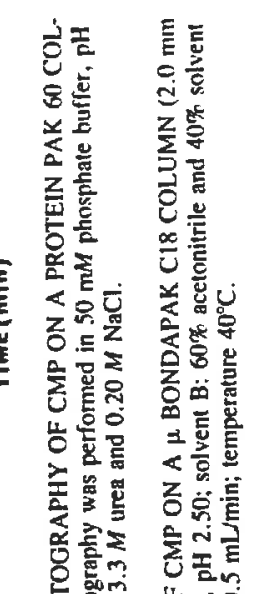

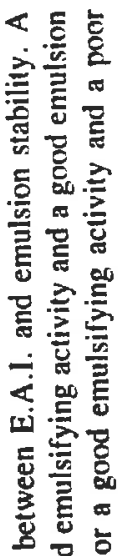

पु

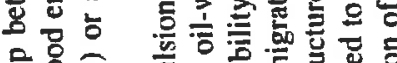
을

땡

壖吉

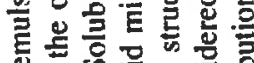

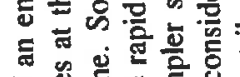

论

后家宫它

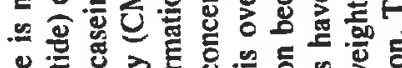

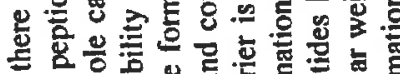

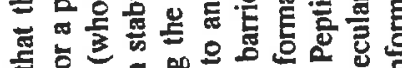

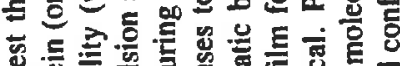

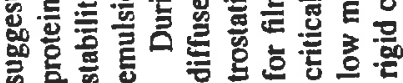

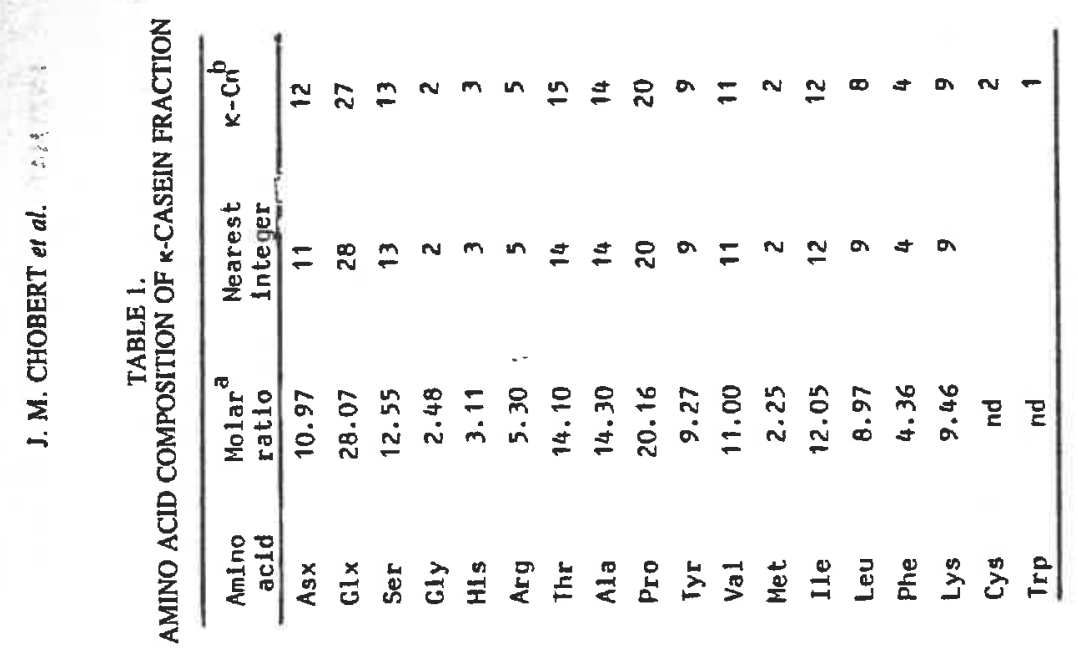

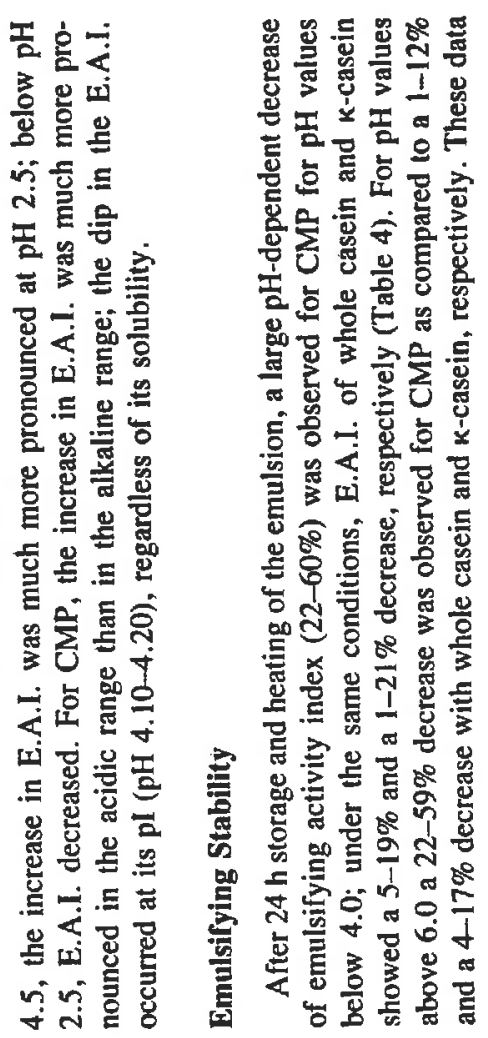




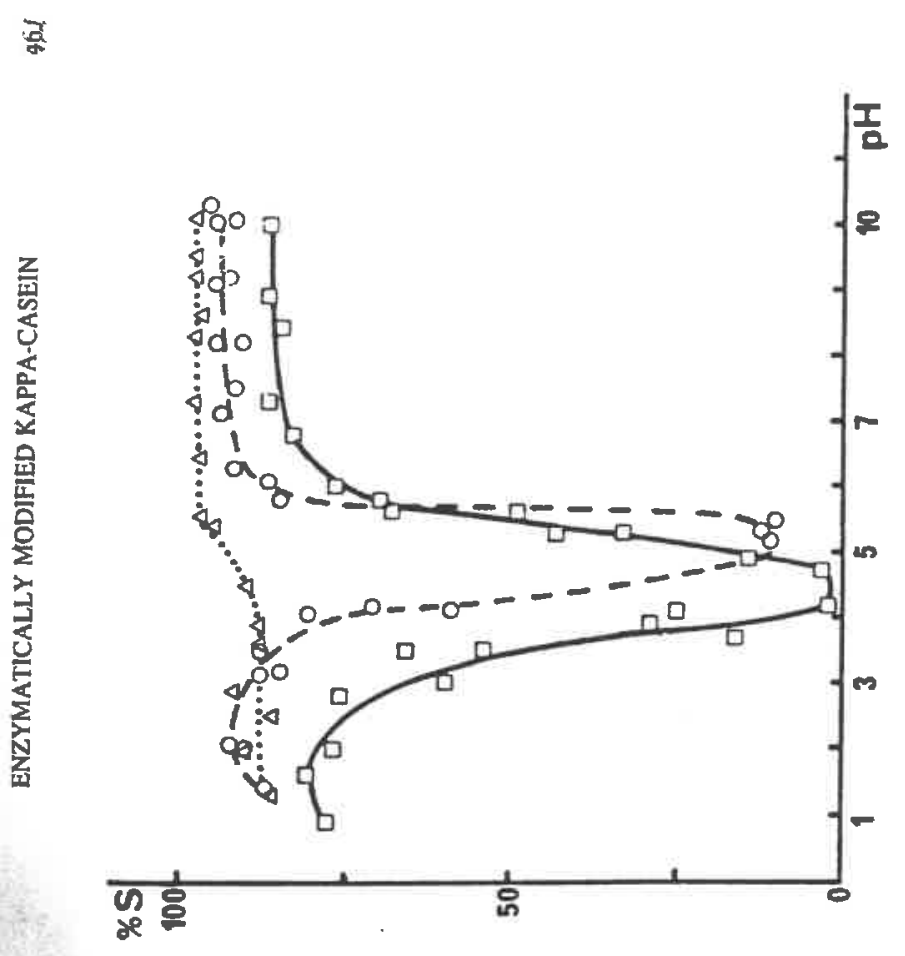

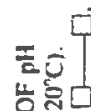

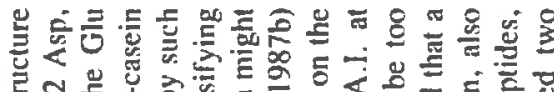
은 它

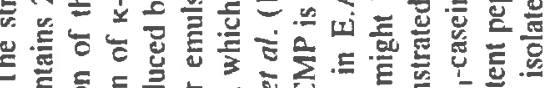

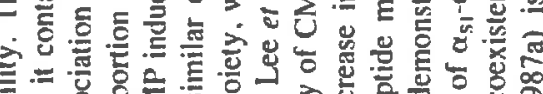

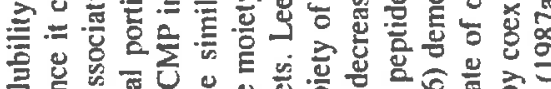

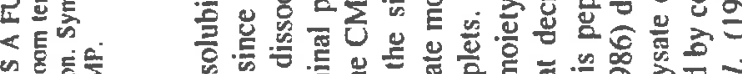

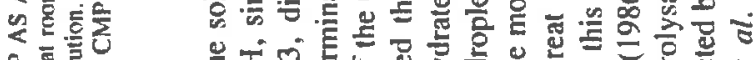

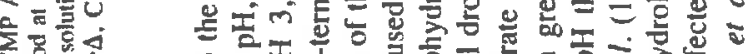

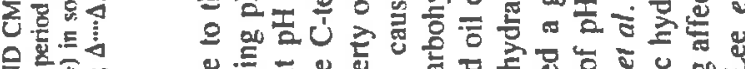

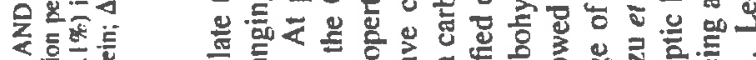

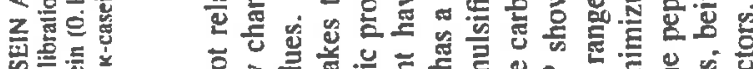

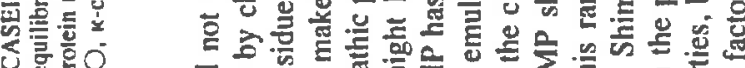

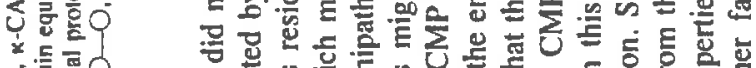

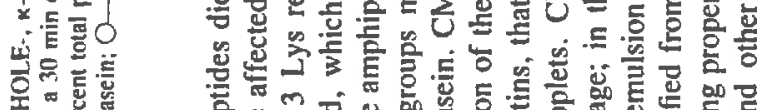

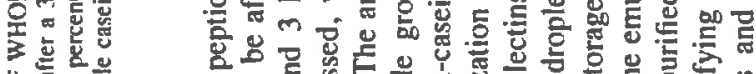

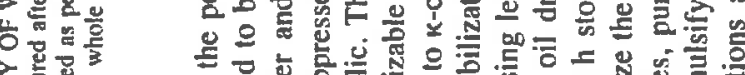

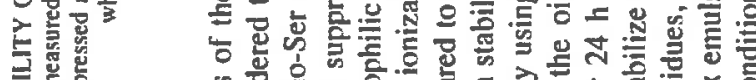

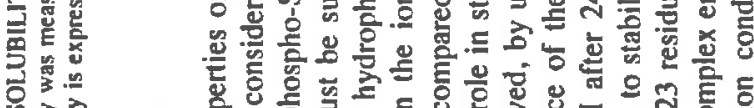

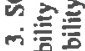

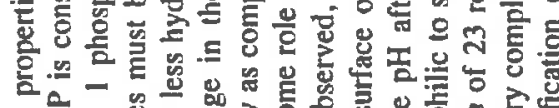

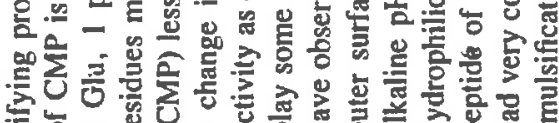

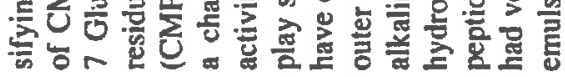

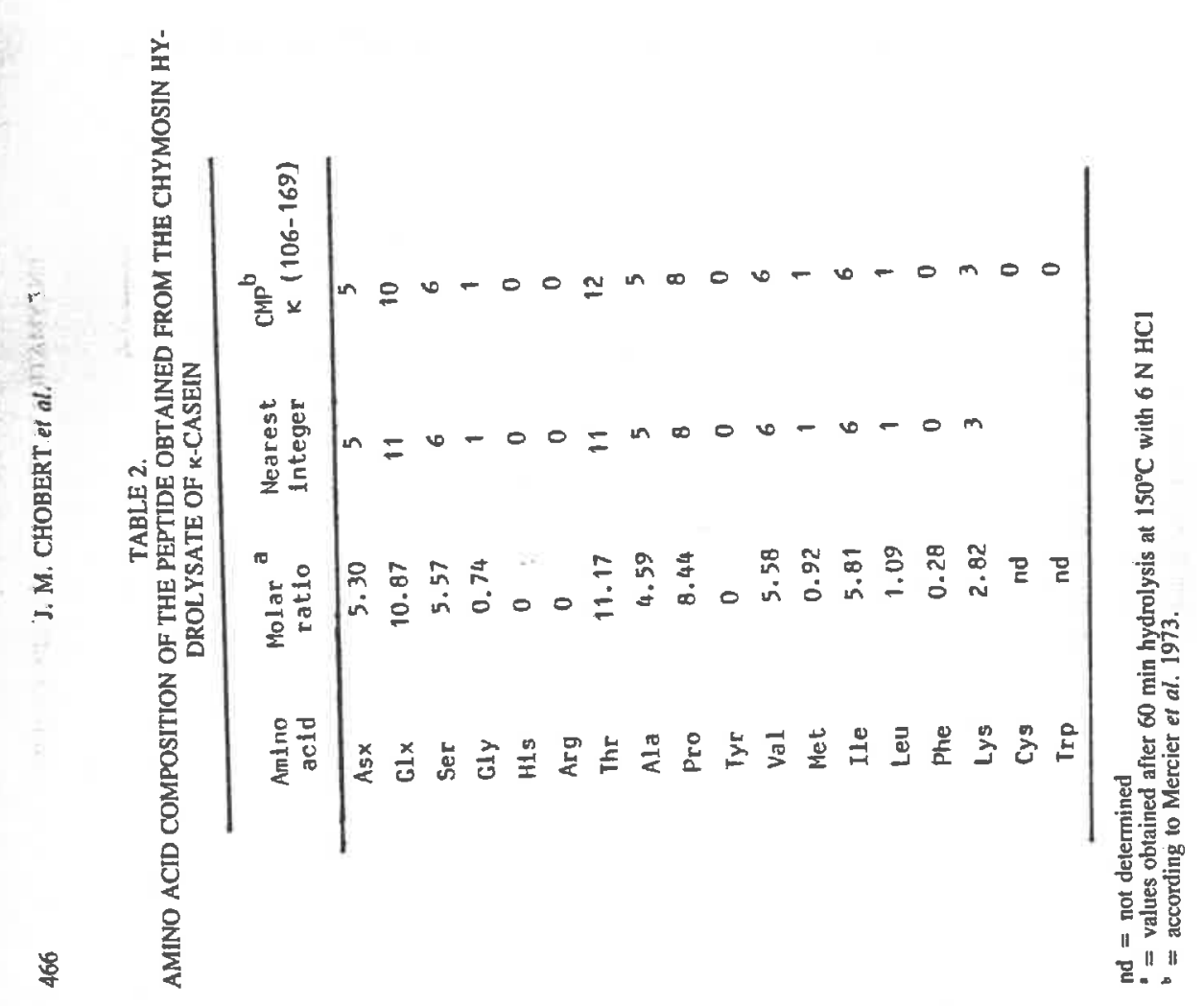

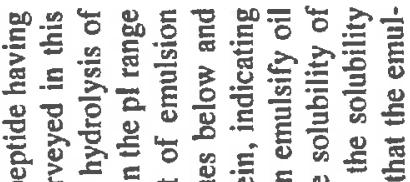

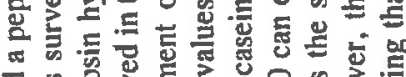

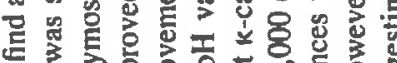

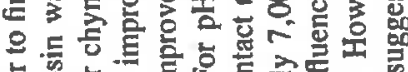

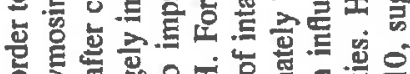

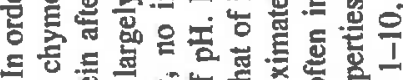

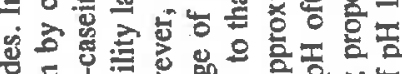
들

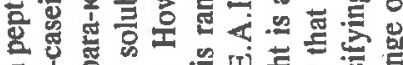

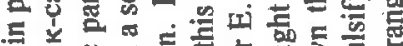

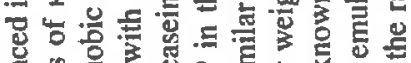

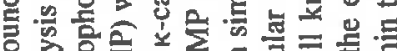
일

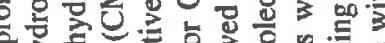

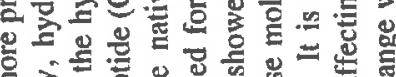

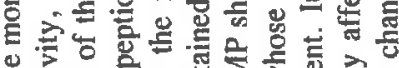
8 충

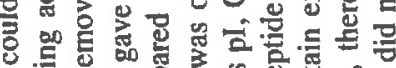

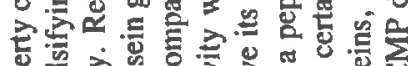

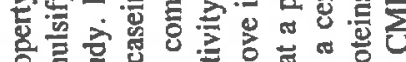

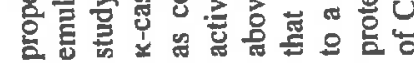




\begin{tabular}{|c|c|c|c|c|c|c|}
\hline $00^{\circ} \angle L \mp E L L$ & $8 L^{\circ} \angle 2 \mp+7 Z 2$ & $68^{\circ} 02 \mp 802$ & $\varepsilon 0^{\circ} \downarrow \downarrow \mp 9 \varepsilon Z$ & $61.1 \mp 952$ & $00.9 \mp 182$ & 6 \\
\hline $0 Z^{\circ} \varepsilon L \mp S \varepsilon L$ & $56+1=002$ & $19 \cdot \varepsilon l \mp L 6 \downarrow$ & $26 \% \mp 012$ & $00.61 \mp \angle 52$ & $00.5=S L 2$ & 8 \\
\hline $89 \cdot \mathrm{SL} \mp 92 \mathrm{~L}$ & $1 \varepsilon^{\circ} 02 \mp 76 t$ & 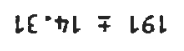 & $S 8 \cdot 2 L \mp+702$ & $00 \cdot 12=412$ & $05^{\circ} 21 \mp 2 E Z$ & $L$ \\
\hline$L / 181 \mp 90 L$ & $0+7.9 \mp 612$ & $22 \cdot 82 \mp 6 L 1$ & $05 \cdot 1 L \mp 202$ & $00 \cdot 61 \mp l \angle l$ & $00 \cdot 9 \mp E 6 L$ & $\varepsilon$ \\
\hline $\begin{array}{c}82 \cdot 6 \mp L S L \\
\theta 7\end{array}$ & $\mathrm{EO}^{-2} \underset{0_{7}}{\mp}$ & $\begin{array}{c}90 \cdot+1 \mp+81 \\
07\end{array}$ & $\begin{array}{c}2 \varepsilon^{\circ} 0 \mathrm{~L} \mp 06 \mathrm{l} \\
0_{7}\end{array}$ & $\begin{array}{c}92^{\circ} \varepsilon \mp 781 \\
\theta 7\end{array}$ & $\begin{array}{c}68.5 \mp 161 \\
0_{7}\end{array}$ & 2 \\
\hline
\end{tabular}

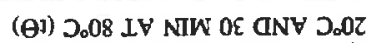

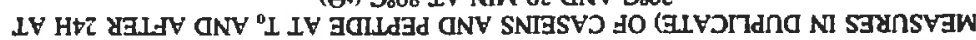

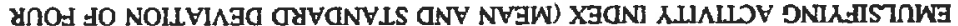
$\varepsilon$ Iา8YI
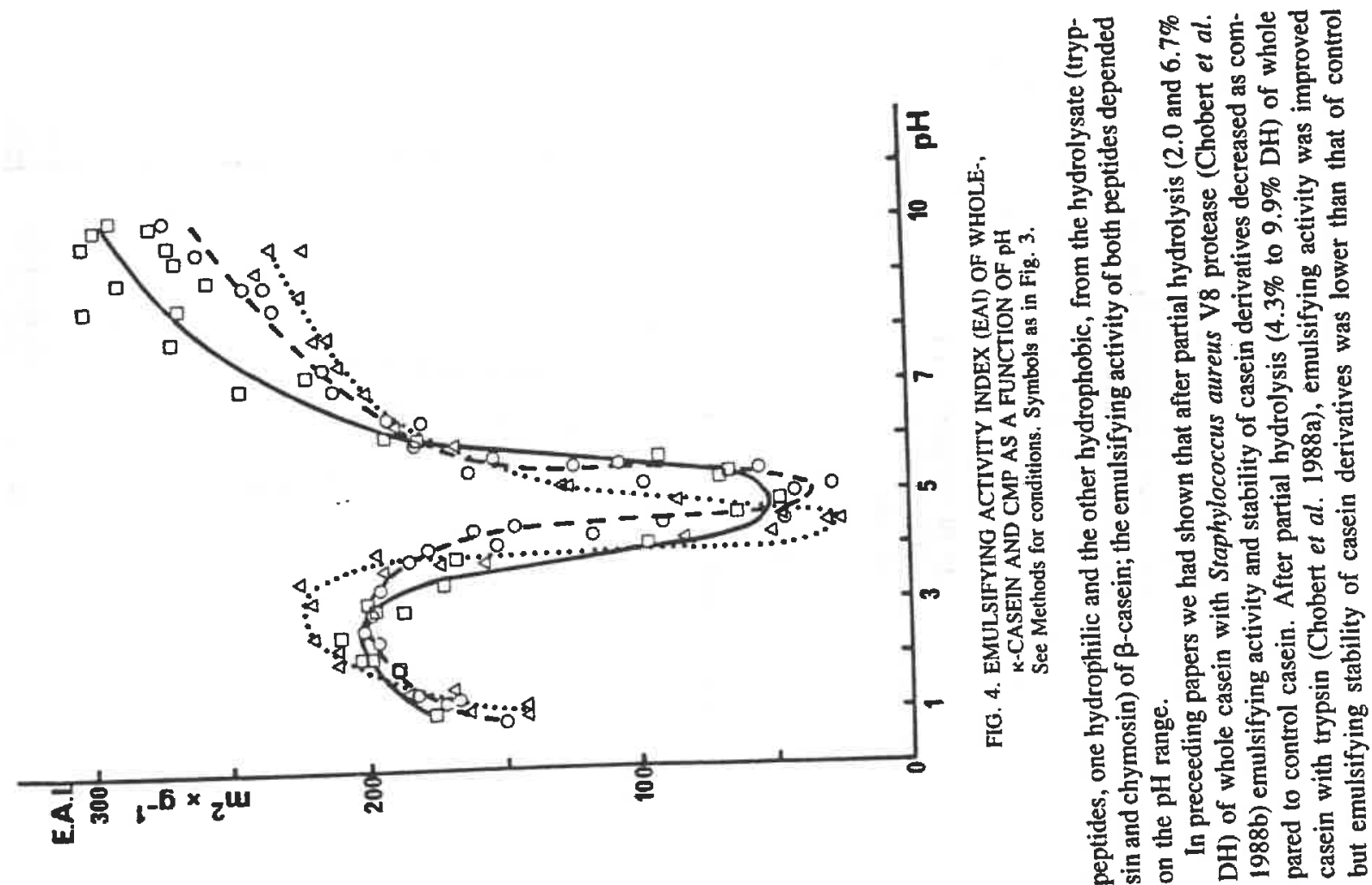


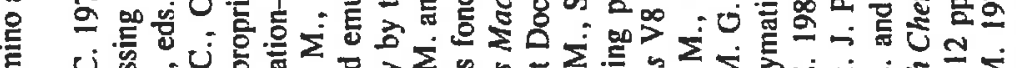

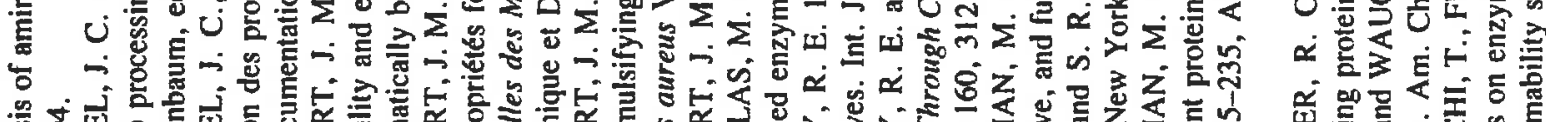

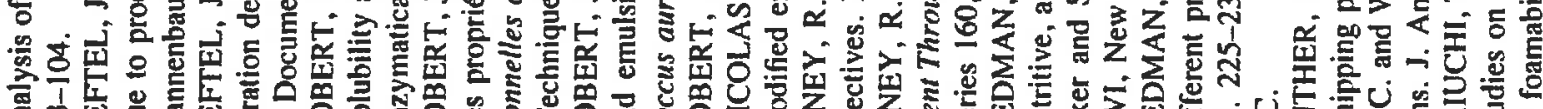

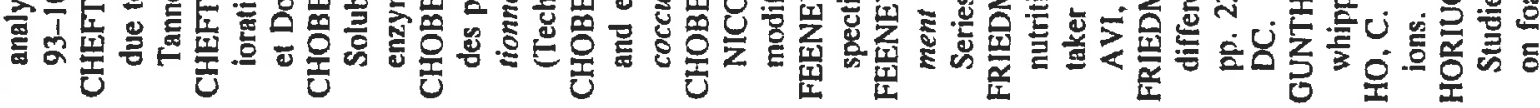

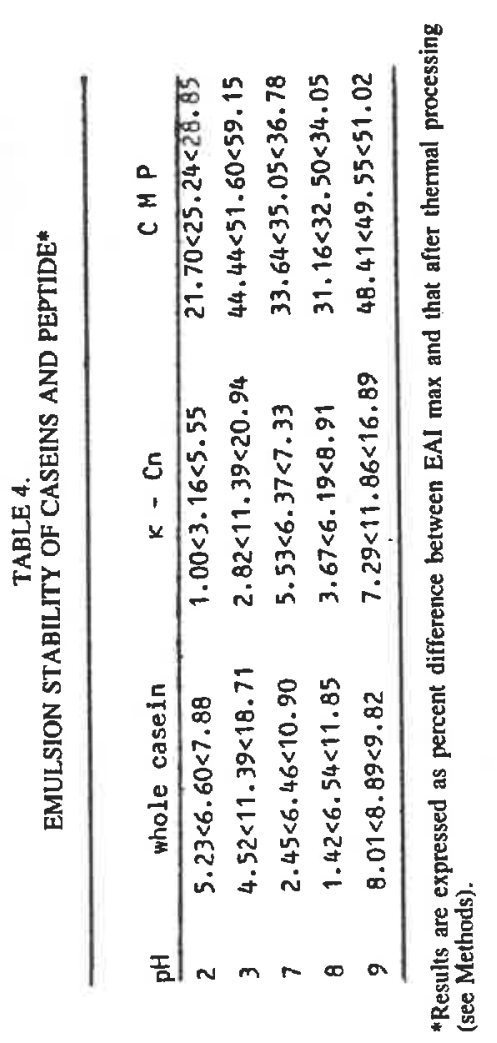

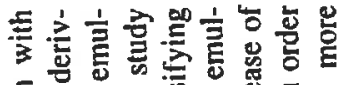

등. 는 要

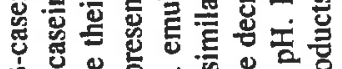

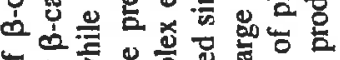

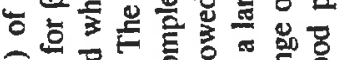

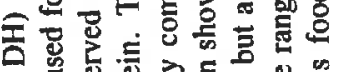

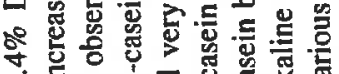

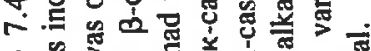

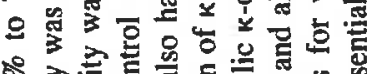

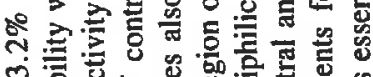

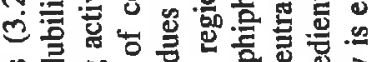

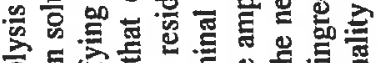

를 혼.

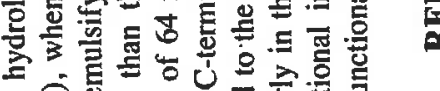

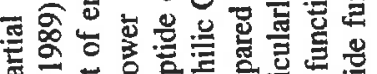

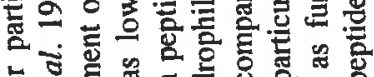

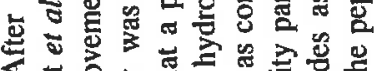
<

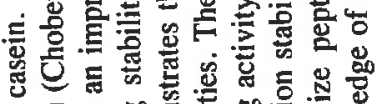

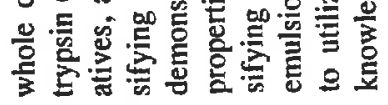

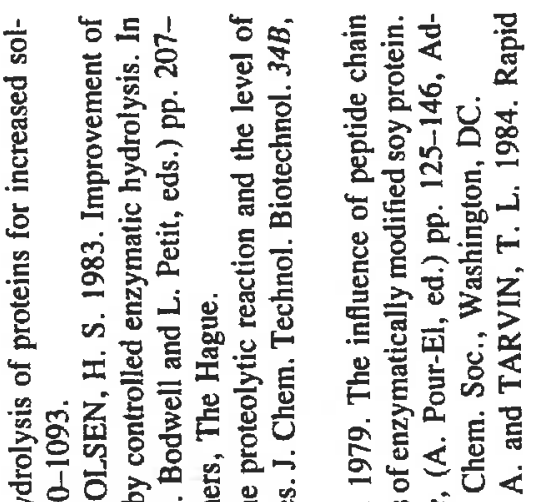

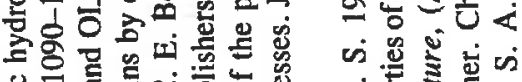

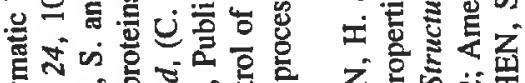

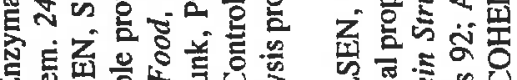

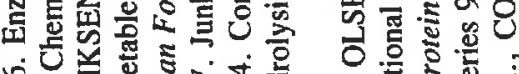

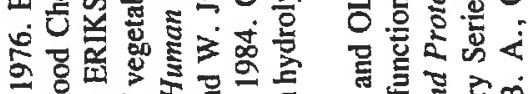

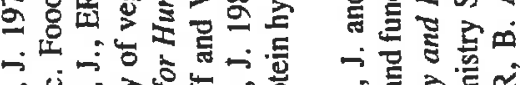

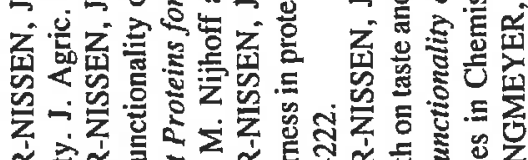

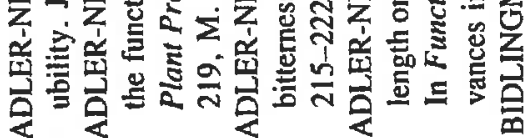



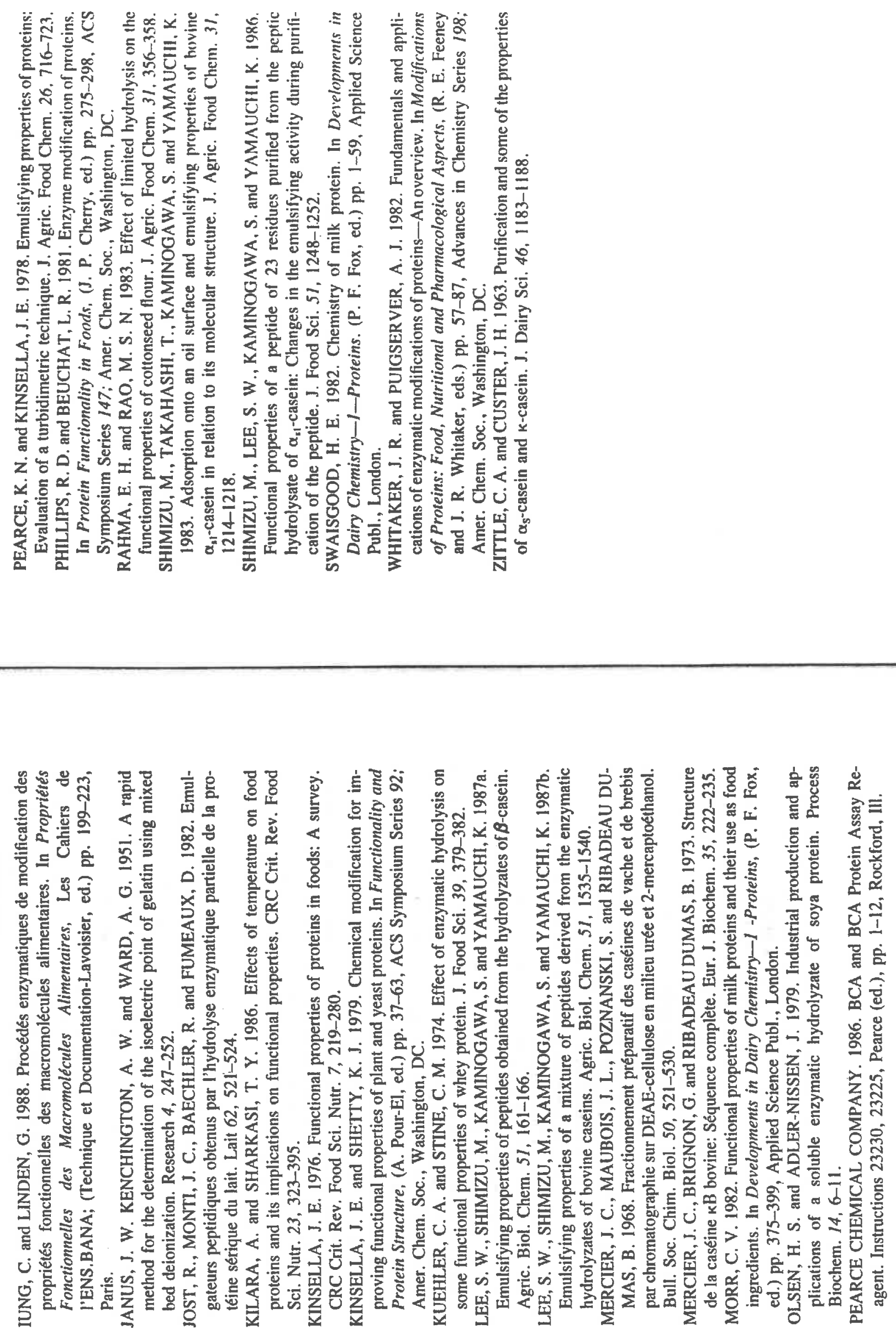